Orginal Article

\title{
Knowledge and Attitude Regarding HIV/AIDS Among Army Personnel at Army Hospital
}

Darai B.+

\begin{abstract}
s
Armies are vulnerable to HIV/AIDS due to various reasons. One of them is they have to go to different parts of the country and outside it while carrying on their duties and responsibilities leaving their wives and families at home. According to the report prepared by New Era in 1994 armies were found to be the main-consumer of prostitution at the border areas.
\end{abstract}

This study reported the result of survey conducted among army personnel's knowledge and attitude on HIV/AIDS. Data were collected from 100 respondents of Army Hospital, Chhauni, Kathmandu. The study was done using a descriptive method.

The study showed that personnel's holding higher ranks had higher knowledge and attitude score as compared to the personnel's in lower ranks. Army personnels attending orientation class on HIV/ AIDS had significantly higher knowledge score than those not attending. This suggests that orientation class or in-service education about HIV/ AIDS to the staff is helpful in order to make them knowledgeable about it. Results of t-test indicate a significant difference ( $\mathrm{p}-0.05)$ between mean knowledge scores. Recommendation from this study is to provide the in-service education to all army personnel's about HIV/AIDS.

(Keywords- Knowledge, Attitude, Army people, HIV/AIDS)

\section{Introduction of the Study:}

AIDS is a global problem. It threatens every recent step of progress in most of the developing countries. The whole world is badly affected by this fatal epidemic caused by RETRO VIRUS. It is transmitted mainly from sexual contact, blood, and infected mother to fetus etc. The treatment has not

+ Mrs. Bina Darai, BN

Lt., Nursing Officer

Shree Birendra Hospital, Chhauni been discovered, but many research studies an $\mathrm{p}$ investigations are working towards a vaccination $\mathrm{l}$ In 1981, the USA for the first time recognized AID $F$ as a disease. Since then 36.1 million people hav been infected with HIV/AIDS throughout the worl and 20.8 million people have already died of $i$ WHO/UNAIDS estimates that more than 52 millio men, women and children have been infected wit 1 HIV worldwide since the beginning of the epidemic : As of 30 June 2003, 160,000 AIDS cases have bee $t$ reported in the south-east region of Asia. More tha c $95 \%$ of this was reported from four countries onl 1 namely Thailand, India, Cambodia and Myanmai .

In Nepal, the first AIDS case was detected $\mathrm{i} 1$ 1988. At first, the growing rate of HIV/AIDS wa slow, but now it is increasing more rapidly According to one official record(National centre fo AIDS and Control Oct. 31,2004) at least 226 peopl have already lost their lives because of AIDS, 83: persons have full blown AIDS and 4354 person have been confirmed HIV positive in Nepal. Mail route of transmission is sexual and IDV.

The situation in Nepal, though not frightening, i quite serious - due to open border with India when HIV/AIDS is spreading at the highest speed Migrant and seasonal workers from both sides cros the border during the whole year. Another facto that causes fear is girl trafficking. According t Maiti Nepal, 2004, more than 7000 Nepali girls ar moved to India every year for prostitution.

There are approximately more than two hundre thousands Nepali females who are currentl working in the sex industry throughout India. Whe they are found positive for HIV, they are forced return and spread the disease in Nepal.

Since no red-light area exists legally in Nep: commercial sex workers carry out their busine creating the risk behaviours which are ve complicated to trace. HIV/AIDS is also spreadi in Nepal via drug addicts sharing contaminat 
needle. Other reasons of increasing HIV/AIDS rapidly are poverty, illiteracy, and lack of proper information on transmission of AIDS and its prevention, lack of screening facilities in laboratories. ${ }^{+}$

From different sources, it has been found that army personnel's are a high-risk group of HIV/AIDS. Orientation class about HIV/AIDS has not been done among most of them, and they do not take it seriously because of social/ family distance and are seemingly insensitive to its dangerous effects. They have to go to different parts of the country as well as outside the country while undertaking duties and responsibilities. According to the New Era Reports of 1994. at the border side, main consumers of prostitution were found to be army personnel. ${ }^{\text {s }}$

Therefore, for the prevention of this disease, all people including army personnels should be aware of the AIDS and its prevention. After a massive awareness on HIV/AIDS created among army personnel, they can prevent and protect themselves from this disease. So, adequate information on it has to be provided to them in order to prevent themselves from contacting HIV/AIDS.

\section{Research objectives:}

To access knowledge and attitude of the army personnel about HIV/AIDS.

\section{Significance of Study:}

1. According to Dr. Deepak Manral from Action Aid in 1994, army personnel are one of the high risk groups of HIV/AIDS. They are separated from their families for a long time in the course of their duties and responsibilities. They have to go to different parts of the country and beyond for the peacemaking programs. But most of them have not attended orientation class about HIV/AIDS. Moreover, most of them do not take it seriously because of social and family distance thus seeming to be insensible to its dangerous effects.

This small study will help nurses and policyformulators to priortitize health education about HIV/AIDS prevention among army clients.
2. World AIDS Campaign, 2000 focused on the slogan "Men Make a Difference." Because:

i) Men's health is important but they don't give adequate attention to their bodies.

ii) Men's behaviour puts them at risk of HIV.

iii) Men's behaviours put women at risk of HIV.

iv) Unprotected sex between men endangers both men and women.

v) Men need to give greater consideration to AIDS as it affects the family.

Most of the Nepalese army personnel are men. This small study will help follow the slogan of World AIDS Campaign, 2000 and motivate men especially army personnel to change their behavior.

\section{Research Method}

A simple descriptive survey method was employed in this study. The study areas were Out Patient Department of Medical, Surgical, Chest, Eye and ENT unit of Army Hospital (Chhauni). All army personnels who came to visit Medical, Surgical, Chest, Eye and ENT, Out Patient Department of Army Hospital Chhauni and who met inclusion criteria were considered as population for this study. A total of 100 subjects were interviewed.

\section{Results of Study}

Data were analysed from 100 respondents. Among them 50 were from the higher ranks and 50 were from the lower ranks. Obtained data were analyzed and interpreted on the basis of objectives and research hypothesis of the study. The major findings of this study are presented into 3 parts.

$\square$ The Demographic Information.

$\square$ Knowledge about HIV/AIDS.

口 Attitudes towards HIV/AIDS.

\section{Demographic Information:}

In the demographic information of the respondents, Rank, Age, Attended UNIFIL. Attitude Orientation Class about HIV/AIDS were included. 


\begin{tabular}{|c|c|c|}
\hline Variables & Frequency & Percentage \\
\hline \multicolumn{3}{|l|}{ Rank } \\
\hline \multicolumn{3}{|l|}{ A. Higher Rank } \\
\hline a. Jamdar & 14 & 14 \\
\hline b. Subedar & 14 & 14 \\
\hline c. Lieutenant & 6 & 6 \\
\hline d. Captain & 16 & 16 \\
\hline B. Lower Rank & & \\
\hline a. Soldier & 25 & 25 \\
\hline b. Lance Nayak & 6 & 6 \\
\hline c. Nayak & 4 & 4 \\
\hline d. Hawaldar & 15 & 15 \\
\hline \multicolumn{3}{|l|}{ Age } \\
\hline a. $18-29$ years. & 34 & 34 \\
\hline b. Above 30 years. & 66 & 66 \\
\hline \multicolumn{3}{|l|}{ Educational Level } \\
\hline a. $5-10$ class & 48 & 48 \\
\hline b. S.L.C. & 21 & 21 \\
\hline c. I.A. & 13 & 13 \\
\hline d. B.A. & 16 & 16 \\
\hline e. Above B.A. & 2 & 2 \\
\hline \multicolumn{3}{|l|}{ Attended Orientation Class About HIV/AIDS } \\
\hline a. Yes & 42 & 42 \\
\hline b. No & 58 & 58 \\
\hline \multicolumn{3}{|l|}{ Attended UNIFIL } \\
\hline a. Yes & 60 & 60 \\
\hline b. No & 40 & 40 \\
\hline
\end{tabular}

Table - 1: Frequency and percentage distribution of respondents according to Demographic Information:

Frequency Polygon of HIV/AIDS Overall Knowledge Secores of Army personal.

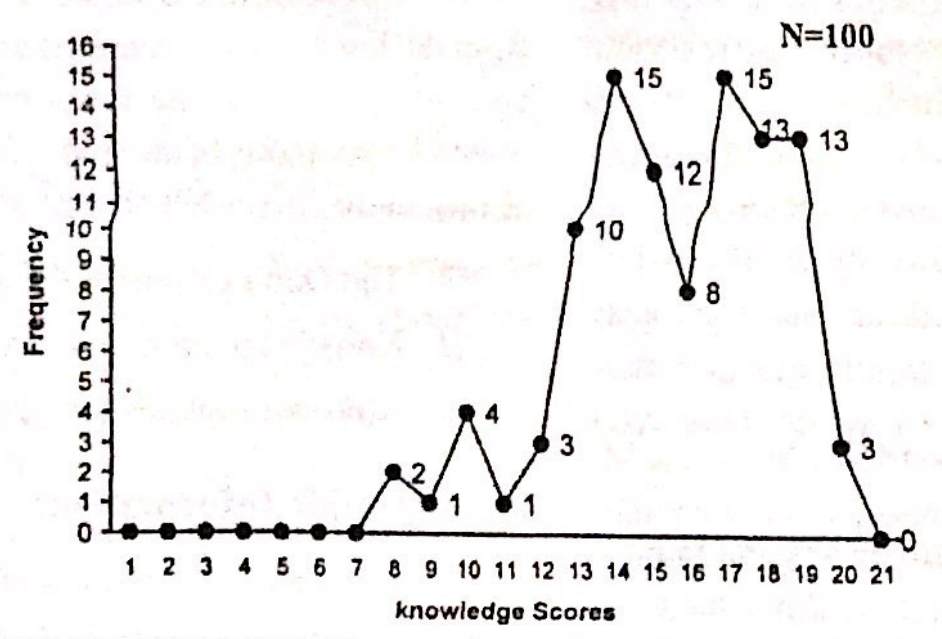

Figure - 1: Showing Frequency polygon distribution of HIV/AIDS overall knowledge scores of army personal. 


\begin{tabular}{|l|l|l|l|l|}
\hline Rank & Number & Mean & S.D. & P. value \\
\hline Higher Rank & 50 & 16.46 & 2.43 & \multirow{2}{*}{$\mathrm{P}=.001$} \\
\hline Lower Rank & 50 & 14.66 & 2.85 & \\
\hline Total & 100 & 31.12 & 5.28 & \\
\hline
\end{tabular}

Table -2: Mean knowledge score regarding HIV/AIDS according to rank of Respondents

$\mathrm{N}=100$

\begin{tabular}{|l|c|c|c|c|}
\hline Orientation Class & No. of Respondents & Mean & S.D. & P. Value \\
\hline Attended & 42 & 16.95 & 2.10 & \multirow{2}{*}{ P $=000009$} \\
\hline Not Attended & 58 & 14.55 & 2.79 & \\
\hline Total & 100 & 31.50 & 4.89 & \\
\hline
\end{tabular}

$\mathrm{P}<0.05$

Table - 3; Mean knowledge score of respondents according to the attending orientation class about HIV/AIDS:

\begin{tabular}{|c|c|c|c|c|}
\hline & & & & \\
\hline Age group & Numbers of respondents & Mean & S.D. & P. value \\
\hline $18-29$ years & 34 & 15.20 & 2.67 & \multirow{3}{*}{$P=0.36$} \\
\hline Above 30 years & 66 & 15.74 & 2.84 & \\
\hline Total & 100 & 30.94 & 5.51 & \\
\hline
\end{tabular}

Table - 4: Mean knowledge score of respondents according to age of Army Personnel

$$
P>0.05
$$

$\mathrm{N}=100$

\begin{tabular}{|l|c|c|c|}
\hline Sub scale & Number of questions & Higher Rank & Lower Rank \\
\cline { 2 - 4 } & & Correct Response (\%) & Correct Response (\%) \\
\hline $\begin{array}{l}\text { Mode of transmission } \\
\text { of HIV/AIDS. }\end{array}$ & 10 & 82.0 & 73.6 \\
\hline $\begin{array}{l}\text { Sign and symptoms of } \\
\text { AIDS }\end{array}$ & 5 & 65.6 & 52.4 \\
\hline $\begin{array}{l}\text { Preventive measures of } \\
\text { HIV/AIDS }\end{array}$ & 4 & 95.5 & 90.5 \\
\hline
\end{tabular}

Table - 5: Percentage distribution of correct response of knowledge sub scale according to the rank of respondents

\begin{tabular}{|l|c|c|c|}
\hline Education level & Numbers of respondents & Mean & Standard deviation \\
\hline 5-10 & 48 & 14.66 & 3.06 \\
\hline SLC & 21 & 15.90 & 2.21 \\
\hline IA & 13 & 16.76 & 2.55 \\
\hline BA & 16 & 16.5 & 1.93 \\
\hline Above BA & 2 & 18.5 & 0.70 \\
\hline Total & 100 & 82.34 & 10.45 \\
\hline
\end{tabular}

Table - 6: Mean knowledge score of respondents regarding HIV/AIDS according to the educational level. 
Percentage distribution of correct response of respondents according to orientation class attended in three areas of knowledge

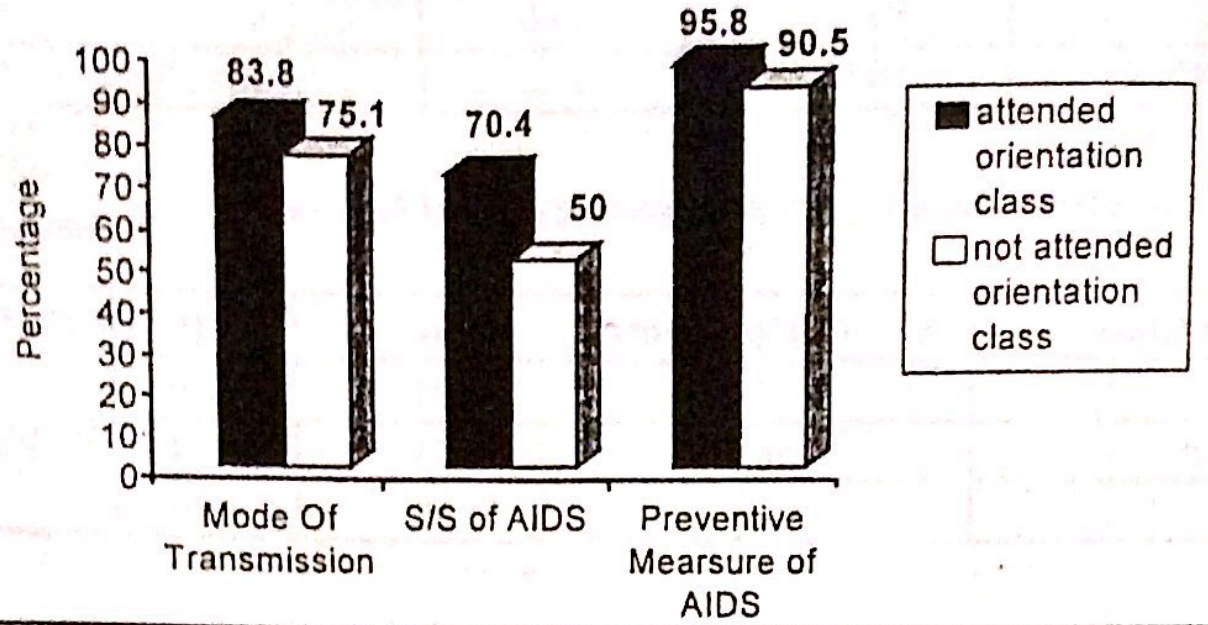

Figure-2: Showing Percentage distribution of correct response of respondents according to orientation class attended in three areas of knowledge

\begin{tabular}{|c|c|c|}
\hline Positive attitude score & Frequency & Percentage \\
\hline 12 & 4 & 4 \\
\hline 11 & 65 & 65 \\
\hline 10 & 18 & 18 \\
\hline 09 & 8 & 8 \\
\hline 08 & 3 & 3 \\
\hline 06 & 1 & 1 \\
\hline 05 & 1 & 1 \\
\hline Total & $\mathbf{1 0 0}$ & $\mathbf{1 0 0}$ \\
\hline $\mathbf{M}=\mathbf{1 0 . 5} \quad$ SD $=\mathbf{1 . 0 8}$ & &
\end{tabular}

Table - 7: Frequency and percentage distribution of overall positive attitude score of respondents:

\begin{tabular}{|l|c|c|c|c|}
\hline Rank & No. & Mean & SD & P. value \\
\hline Higher Rank & 50 & 10.54 & 1.03 & \multirow{2}{*}{ P = 0.71 } \\
\hline Lower Rank & 50 & 10.46 & 1.14 & \\
\hline Total & 100 & 21.0 & 2.17 & \\
\hline
\end{tabular}

Table - 8: Mean positive attitude score of respondents according to rank

\begin{tabular}{|l|c|c|c}
\hline Orientation Class & No. of respondents & Mean & S.D. \\
\hline Attended & 42 & 10.61 & 1.08 \\
\hline Not Attended & 58 & 10.41 & 1.09 \\
\hline Total & $\mathbf{1 0 0}$ & $\mathbf{2 1 . 0 2}$ & $\mathbf{2 . 1 7}$ \\
\hline
\end{tabular}

Table - 9: Mean positive score of respondents regarding HIV/AIDS according to orientation class attended about HIV/AIDS. 
$N=100$

\begin{tabular}{|l|c|c|c|}
\hline Age groups & No. of respondents & Mean & S.D. \\
\hline 15.29 years & 34 & 10.52 & 0.92 \\
\hline Above 30 years & 66 & 10.48 & 1.16 \\
\hline Total & 100 & 21.00 & 2.08 \\
\hline
\end{tabular}

Thble - 10: Mean positive attitude score of respondents regarding HIV/AIDS according to age

Percentage distribution of positive nttitude score of respondents regarding HIV/AIDS according to educational level

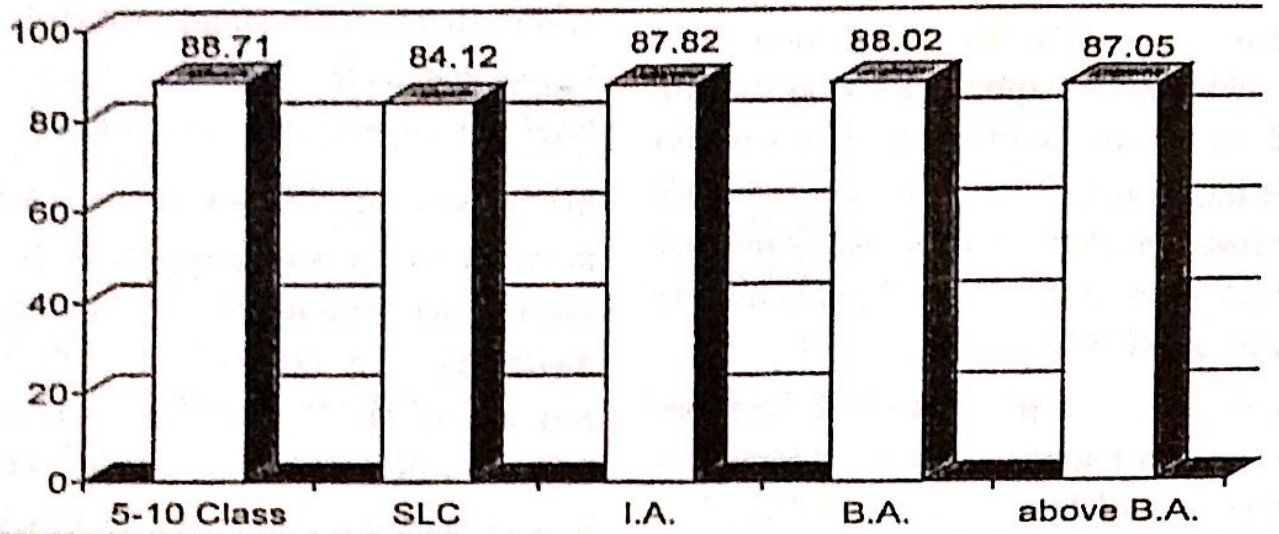

Figure-3: Showing percentage distribution of positive attitude score of respondents regarding HIV/AIDS according to educational level

Summary, Conclusion and Recommendation:

This chapter presents the summary of the significant findings.

\section{Summary of the findings:}

This study was conducted to explore the current knowledge of army personnel about HIV/AIDS in the selected OPDs of the Army Hospital. The data were collected within a two weeks period from 100 respondents.

1. $100 \%$ of the respondents had heard about HIV/ AIDS.

2. $20 \%$ of the respondents had received information from radio, $11 \%$ from T.V., $11 \%$ from news papers, $12 \%$ from others (health personnel, friends), and $46 \%$ from all the above.

3. $25 \%$ of the respondent had heard about homosexuality in their camps and $75 \%$ had not heard about homosexuality in their camps.

4. The overall mean knowledge score of respondents was 15.32 with he standard deviation of 2.7 .

5. Higher rank respondents had a higher mean knowledge score of 16.46 with the standard deviation of 2.43 than lower rank respondent at 14.66 with the standard deviation of 2.85 . There was a significant difference in knowledge score according to rank. The ' $\mathrm{p}$ ' value was $<0.05$ levels. This hypothesis was statistically accepted.

6. The orientation class attended respondents had a higher mean knowledge score of 16.95 with the standard deviation of 2.10 . The unattended respondents had a score of 14.55 with the standard deviation of 2.79 . There was a significant difference in the mean knowledge score. The 'p' value was $<0.05$ levels. This hypothesis was statistically accepted.

7. The mean knowledge score of the respondents aged above 30 was 15.74 with the standard deviation of 2.84. Respondents with ages ranging from 18-29 years of age were 15.20 with the standard deviation of 2.67. There was not a significant difference in the mean knowledge score. ' $p$ ' value was $>0.05$ level. Statistically this hypothesis was not accepted.

8. Higher ranking respondents had a higher knowledge score in all areas of knowledge (82\% in the areas of mode of transmission, $65.6 \%$ in the areas of signs and symptoms, and 
$95.5 \%$ in the areas of preventive measures) than lower ranking respondents $(73.6 \%$ in the area of mode of transmission, $52.4 \%$ in the area of sign and symptoms, and $90 \%$ in the area of preventive measures of HIV/AIDS).

9. Respondents who attended the orientation class had a higher knowledge in all areas of knowledge $183.8 \%$ in the areas of mode transmission, $70.4 \%$ in the areas of sign and symptoms. $95.8 \%$ in the preventive measures). Those respondents who did not attend orientation class had a smaller knowledge score $(75.1 \%$ in the areas of mode of transmission, $50 \%$ in sign and symptoms, and $90.5 \%$ in the areas of preventative measures of HIV/AIDS).

10. Respondents who were above SLC level had a higher mean knowledge seore (IA - 16.76 with the standard deviation of $2.55 . \mathrm{BA}-18.5$ with the standard deviation of 0.70 and below SLC level respondem had a lesser mean knowledge score $(5-10$ class - 14.66 with standard deviation of 3.06 . SLC - 15.90 with the standard deviation of 2.21 ).

11. The mean positive atutude score of higher ranking respondents was 10.54 with the standard deviation of 1.03 . Lower ranking respondents had 10.46 with the standard deviation of 1.14. There was no significant difference in the mean positive attitude scores. The ' $\mathrm{p}$ ' vahe was $>0.05$ level. Statistically this hypothesis was not accepted.

12. In relation to education, higher SLC levels had higher positive attitude scores (IA $-87.82 \%$. BA - 88.02\%, above BA - 87.05\%). Lower SLC level respondents had lesser positive attitude scores $(5-10$ class $-88.71 \%$, SLC $84.12 \%)$. According to the educational level, there was no difference in positive attitude scores.

13. Regarding the mean positive attitude scores of respondents according to orientation class and age, there were no significant differences in the mean positive attitude scores.

\section{Discussion}

The findings revealed that higher ranking respondents had a higher mean knowledge score of 16.46 with the standard deviation of 2.43 th the lower ranking respondent's 14.66 with standard deviation of 2.85 . There was a signific difference. The ' $p$ ' value was $<0.05$.

The respondents who attended orientation class! a higher mean knowledge score of 16.95 with standard deviation of 2.10 than the respondents $v$ didn't attend (14.55 with the standard deviation 2.79 ). There was a significant difference in knowledge scores since the ' $\mathrm{p}$ ' value was $<0$ level. This hypothesis was accepted.

In relation to age, there was no significant differe in the mean knowledge scores between above years of age respondents (15.74 with the stand deviation of 2.84) and 18 - 29 years of : respondents (15.20 with the standard deviation 2.67). $P$ value was $>0.05$ levels. Statistically $t$ hypothesis was not accepted. This may due to $\mathrm{sm}$ sample size and no equal number of samp between these two groups.

There was also no significant difference in positive attitude score between higher-rank respondents and lower ranking respondents. T 'p' value was $>0.05$ levels, so, statistically t hypothesis was not accepted. This may he happened because most of the lower ranki respondents may have attended the HIV/AI orientation class.

According to the educational level, there was o a slight difference between the knowledge sco and positive attitude scores regarding HIV/AII.

\section{Conclusions}

Conclusions are based on the findings of the stu The following conclusions have been drawn:

* Knowledge about HIV/AIDS was significa higher in the higher-ranking respondents $t$ the lower-ranking respondents.

* Army Personnel, who have attended orientation class, had significantly hig knowledge scores regarding HIV/AIDS.

* There was no significant difference betw the knowledge scores of respondents aged years and above and $18-29$ aged responde 
* There was no significant difference in positive attitude scores towards HIV/AIDS between the higher-ranking and lower ranking respondents. Though some of the respondents had better knowledge of HIV/AIDS, it is essential to give health education/teaching about HIV/AIDS to all army personnel in order to prevent an increasing number of HIV/AIDS.

\section{Implication of findings}

Despite some of the limitations of this small-scale study, it highlights a number of important implications for the following:

\section{Administrator and Policy Maker}

The findings help higher authority and policy makers to develop health education programs for all army personnel with HIV/AIDS.

\section{Health Educator}

The study helps health educators to educate and motivate army personnel to change their behavour, which can be a high risk for HIVAIDS.

\section{For Nursing Research}

This would provide background to other related studies in the future.

\section{Bibliography}

1. Increasing rate of HIV/AIDS in army people, Kantipur, $9^{\text {th }}$ December 2000.

2. Dr. Jha, T.N.: Facts about AIDS, AIDS Newsletter 10:13, 2000.

3. Dr. Dixon, Patrick: AIDS - an exploding threat, Footsteps 44, 2000.

4. Prostitution in Context of Nepal, The Rising Nepal, Oct. $21^{\text {st }}, 2000$.

5. Fighting against HIV/AIDS, The Rising Nepal, June $10^{\text {th }}, 1999$

6. WHO: AIDS prevention and care whose responsibility? HIV/AIDS infection guidelines, 1997.

7. AIDS/STD health promotion exchange $2: 14$, 1996.

8. Dr. Manral, Deepak: HIV infection and AIDS (A multidimensional introduction), from Kathmandu, Action Aid 4, 1994.

9. WHO: AIDS management, prevention and control program, Geneva 94, 1994. 